\title{
Genetic Diversity and Species Identification of Cultivar Species in Subtribe Cucumerinae (Cucurbitaceae) Using RAPD and SCAR Markers
}

\author{
Juthaporn Saengprajak*, Piyaporn Saensouk
}

Department of Biology, Faculty of Science, Mahasarakham University, Mahasarakham, Thailand.

Email: juthaporn.s@msu.ac.th

Received May 23 ${ }^{\text {rd }}$, 2012; revised June 20 ${ }^{\text {th }}$, 2012; accepted June 30 ${ }^{\text {th }}, 2012$

\begin{abstract}
DNA polymorphism in the cultivar species; Cucumis sativus L., C. melo L. and Benincasa hispida Cogn. of subtribe Cucumerinae (Cucurbitaceae) in the four northeastern provinces of Thailand was examined by using RAPD technique. Twenty 10-mer primers were produced 212 RAPD fragments, ranging from approximately 120 to $2531 \mathrm{bp}$. The genetic similarities were estimated from banding profiles using a NTSYS* version 2.1 as a basis for dendrogram construction via the UPGMA method. Cluster analysis divided the taxa under study into 2 clades. Moreover, a RAPD marker: $\mathrm{Cm}$ (OPJ11 $1_{700}$ ) was specified to C. melo, and this marker was converted into sequence characterized amplified region (SCAR) marker: Cm (SCJ11 $\left.1_{516}\right)$. A pair of sequence-specific primer of clones $\mathrm{Cm}\left(\mathrm{OPJ} 11_{700}\right)$ amplified a distinct single band of the same size as the RAPD clones. The SCAR marker was developed successfully to identify C. melo genotype.
\end{abstract}

Keywords: Cucumerinae; Cucurbitaceae; Genetic Diversity; Random Amplified Polymorphic DNA (RAPD); Sequence Characterized Amplified Region (SCAR); Species Identification

\section{Introduction}

Cucurbitaceae family contains about 90 genera and over 700 species of economic importance [1]. As the plants of this family produce unisexual flowers, cross pollination is a regular feature. Few studies have been reported on the genetic relationship of Cucurbitaceae [2,3]. The evaluation of genetic relationships among the members would promote the efficient use of genetic variations in the breeding program [4]. DNA markers provide an opportunity to characterize genotypes and to measure genetic relationships more precisely than other markers [5].

Molecular biology offers various techniques that can be applied for plant identification. Genetic polymorphism in plants has been widely studied which helps in distinguishing plants at inter- and/or intra-species level [6]. PCR based methods including Randomly Amplified Polymorphic DNA (RAPD) [7] can be effectively used for the study of phylogeny and genetic diversity. RAPD markers have been used for the identification of cultivars and for assessing genetic diversity among cultivars of several crops like mungbean [8], Lotus glaber Mill. populations [9], Pakistani wheat [10], bean [11], pea [12], soybean [13], Ceratotropis [14], etc. Further, development of more specific, sensitive and reproducible

\footnotetext{
*Corresponding author.
}

markers like RAPD based Sequence Characterized Amplified Region (SCAR) can increase industrial application of the molecular techniques [15]. These markers have been used for authentication of plant species of Aquilaria (Thymelaeaceae) [16], Momordica charantia L. [17], Ginseng [18], Artemisia [19], Nepenthes [20] and other commercially important timbers like bamboo [21].

Here we use RAPD method to detect genetic variation and specific fragments among sample species, and converse the RAPD fragment into SCAR marker. Stable specific SCAR marker can help us to distinguish each of Cucumerinae specimens from its closely related species. Therefore, it is necessary to provide an efficient and scientific method for assessing genetic diversity and species identification.

\section{Materials and Methods}

\subsection{Plant Materials}

Cucumis sativus L., C. melo L. and Benincasa hispida Cogn. were collected from the four northeastern provinces of Thailand (Khon Kaen, Udonthani, Leoi and Nongbualamphu Provinces). Dried specimens were deposited at the Department of Biology, Faculty of Science, Mahasarakham University. All plant materials were used for confirming the specificity of the SCAR primer. 


\subsection{Genomic DNA Isolation}

Total DNA was extracted by the method of Doyle and Doyle [22] with minor modifications and adapted to small tissue quantities [23]. Fresh young leaves about 0.2 g were ground in a small mortar and pestle containing liquid nitrogen. The grindate was added to $1 \mathrm{ml}$ of extraction buffer [2\% CTAB (hexadecyltrimethylammonium bromide), $100 \mathrm{mM}$ Tris-HCl buffer, $20 \mathrm{mM}$ EDTA, $1.4 \mathrm{M} \mathrm{NaCl}, 1 \%$ PVP-40, pH 8.0)] containing $1 \mu \mathrm{l}$ of 2-mercaptoethanol added just before use. The extract was incubated for $1 \mathrm{~h}$ at $60^{\circ} \mathrm{C}$ with occasional swirling, mixed with an equal volume of chloroform: isoamyl alcohol (24:1, v/v) and centrifuged at 13,000 rpm for $10 \mathrm{~min}$. The aqueous phase was transferred to a new tube and mixed with $2 / 3$ vol of ice-cold isopropanol. The mixture was left at $-20^{\circ} \mathrm{C}$ for $20 \mathrm{~min}$ and again centrifuged at 13,000 rpm for $10 \mathrm{~min}$. The pellet was washed with $10 \mathrm{mM}$ of ammonium acetate in $76 \%$ ethanol, air dried at room temperature for $2-3 \mathrm{~h}$, and dissolved in $40 \mu \mathrm{l}$ of TE buffer (10 mM Tris-HCl pH 8.0, $0.1 \mathrm{mM}$ EDTA). DNase-free RNase A ( $2 \mu \mathrm{l}$ of a $10 \mathrm{mg} / \mathrm{ml}$ solution) was added, the mixture was incubated at $37^{\circ} \mathrm{C}$ for $30 \mathrm{~min}$ and then stored at $-20^{\circ} \mathrm{C}$. The quantity and quality of DNA was determined using a spectrophotometer by measuring the absorbance at 260 and $280 \mathrm{~nm}$ [24]. On the basis of the spectrophotometer readings, $50 \mathrm{ng} / \mu \mathrm{l}$ solutions were prepared and used for PCR amplification.

\subsection{RAPD-PCR and Identification of Specific RAPD Amplicon}

All plant genotypes were studied for polymorphism using 20 RAPD primers including OPJ primer kit from Operon technologies $^{\circledR}$ (OPJ01-OPJ20). PCR amplifications were carried out according to the method described in Williams et al. [7]. The final reaction volume was $25 \mu \mathrm{l}$ and contained: 1X PCR buffer (Promega ${ }^{\circledR}$ USA), $1.5 \mathrm{mM}$ $\mathrm{MgCl}_{2}, 200 \mu \mathrm{M}$ each of dATP, dGTP, dCTP and dTTP, $1.0 \mathrm{pM}$ of primer, $0.3 \mathrm{U}$ of Tag DNA polymerase, and 4 ng of genomic DNA template. Negative controls with distilled water instead of DNA were included in each run in order to verify the absence of contamination. DNA amplification was conducted on a programmable thermalcycler (Hybaid ${ }^{\circledR}$ USA). Template DNA was initially denatured at $94^{\circ} \mathrm{C}$ for $4 \mathrm{~min}$, followed by 45 cycles of PCR amplification using the following parameters: $1 \mathrm{~min}$ denaturation at $94^{\circ} \mathrm{C}, 1 \mathrm{~min}$ annealing at $36^{\circ} \mathrm{C}$, and $2 \mathrm{~min}$ primer extension at $72^{\circ} \mathrm{C}$. A final 4 min incubation at $72^{\circ} \mathrm{C}$ was allowed for completion of primer extension. Amplification products were electrophoretically resolved on $1.5 \%$ agarose gels with $1 \mathrm{X}$ TBE (40 mM Tris-borate, $1 \mathrm{mM}$ EDTA) containing $0.5 \mathrm{~g} / \mathrm{ml}$ ethidium bromide, and photographed on a UV transilluminator. The size of the amplified products was determined by comparison with a 100 bp DNA ladder size standard.

Twenty decamer primers were evaluated to DNA polymorphism of C. sativus, C. melo and B. hispida. Among these, primer OPJ-11 was consistently amplified as a single, intense band of approximately $700 \mathrm{bp}$ for all the C. melo specimens. The amplicon, which was monomorphic to all the $C$. melo specimens but absent in other species was identified. This band named as Cm $\left(\mathrm{OPJ} 11_{700}\right)$ was selected as putative $C$. melo specific marker.

\subsection{Genetic Diversity Analysis}

Data were scored for the presence or absence of amplification fragments from each RAPD primers, and entered into a binary data matrix. Similarity values from the matrices were used for cluster analyses via the unweighted pair group method with arithmetic mean (UPGMA) method with NTSYS* version 2.1.

\subsection{Cloning and Sequencing of RAPD Fragment}

RAPD fragments (Cm (OPJ11 $\left.11_{700}\right)$ ) were excised from the ethidium bromide stained gels and extracted using a QIAquick Gel Extraction Kit (QIAGEN ${ }^{\circledR}$ Germany) according to the manufacturer's instructions. The recovered DNA fragments were cloned in the pGEM-T-Easy vector system I (Promega ${ }^{\circledR}$ USA) and introduced into competent Escherichia coli strain JM109. Recombinants were identified as white colonies on LB plates with X-gal and IPTG. White colonies were grown in $2 \mathrm{ml} \mathrm{LB}$ medium containing $100 \mu \mathrm{g} / \mathrm{ml}$ ampicillin, and plasmid DNA was isolated from putative recombinants according to the method described in Serghini et al. [25] with minor modifications. An aliquot of purified plasmid DNA was analyzed by PCR, while another aliquot was digested by EcoRI restriction enzyme. The resulting products were run on $1.5 \%$ agarose gels containing $0.5 \mu \mathrm{g} / \mathrm{ml}$ ethidium bromide, and photographed. Again putative positive transformants were evaluated based on the size of the amplification product and the size of the plasmid insert. Plasmid DNA from several promising putative transformants were sequenced on an Applied Biosystems 377 automated sequencer, using the ABI PRISM dye terminator cycle sequencing kit at the DNA Technology Laboratory, Kasetsart University, Kampangsaen Campus, Nakorn Pathom, Thailand.

\subsection{Synthesis of SCAR Primer and PCR Analysis}

Based on the sequence data of cloned RAPD fragment, specific primers were designed with the aid of using the program of GeneFisher (http://bibiserv.techfak.uni-biele 
feld/de/genefisher). Primers were synthesized with a Polygen DNA synthesizer of POLYGEN GmbH (Langen, Germany) at the DNA technology Laboratory. The specific primer was designed by adding 17 bases to the 3 ' end of original random primer that produced the respective RAPD fragment to make SCAR as described by Paren and Michelmore [15]. Amplification of genomic DNA with the SCAR primer consisted of $4 \mathrm{~min}$ pre-denaturation at $94^{\circ} \mathrm{C}$ followed by 35 cycles of $1 \mathrm{~min}$ denaturation at $94^{\circ} \mathrm{C}, 1 \mathrm{~min}$ annealing at $55^{\circ} \mathrm{C}$, and $2 \mathrm{~min}$ extension at $72^{\circ} \mathrm{C}$, with a final extension period of $4 \mathrm{~min}$ at $72^{\circ} \mathrm{C}$, and a hold at $4^{\circ} \mathrm{C}$ until recovery. Amplification products were electrophoresed on $1.5 \%$ agarose gels containing $0.5 \mu \mathrm{g} / \mathrm{ml}$ ethidium bromide, and photographed on a UV transilluminator. The SCAR primer designed was used to amplify DNA obtained from the four species including; C. sativus, B. hispida, Luffa cylindrical L., and C. melo (collected from four northeastern provinces of Thailand). Thermal cycling condition for amplification using SCAR primers was described above.

\section{Results}

\subsection{RAPD-PCR and Identification of Specific RAPD Amplicon}

Initial evaluating of 20 RAPD primers against on C. sativus, C. melo and B. hispida (collected from four northeastern provinces of Thailand) were resulted in the identification of 17 RAPD primers (85\%) that gave 138 polymorphic bands between the plant genotypes. The total 212 bands were amplified using 20 RAPD primers, produced an average of 10 to 11 bands per primer. The number of RAPD fragments that were amplified ranged from 1 to 20 and the sizes ranged from about 120 to 2531 bp (Figure 1).

Of these 20 RAPD primers, primer OPJ11 (5'ACTCCTGCGA-3') was consistently amplified as a single, intense fragment of approximately $700 \mathrm{bp}$ for all the C. melo specimens. The amplicon, which was monomorphic to all the C. melo specimens but absent in other species was identified. This band named as $\mathrm{Cm}$ $\left(\mathrm{OPJ} 11_{700}\right)$ was selected as putative $C$. melo specific marker (Figure 2).

\subsection{Genetic Diversity Analysis}

Based on the presence or absence of 212 RAPD bands, cluster analysis of the genetic similarity estimates was performed using NTSYS* version 2.1 to generate a UPGMA dendrogram shown in Figure 3. The RAPD profiles produced a dendrogram which fully resolved the taxa of Cucumerinae into 2 clades; $C$. sativus (collected from Khon Kaen, Udonthani, Leoi and Nongbualamphu

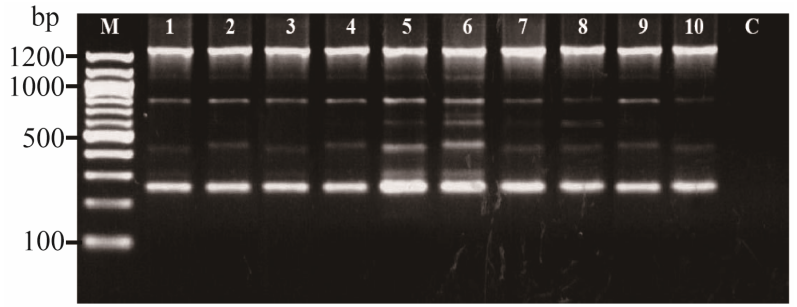

Figure 1. RAPD profiles of Cucumerinae species amplified with OPJ-20 on $1.5 \%$ agarose gel. (M: mole wt marker (100 bp), lane 1 - 4: C. sativus (samples collected from Khon Kaen, Udonthani, Loei and Nongbualamphu, respectively), lane 5 - 8: C. melo (samples collected from Khon Kaen, Udonthani, Loei and Nongbualamphu, respectively), lane 9 - 10: B. hispida (samples collected from Khon Kaen and Loei, respectively), and C: negative control.

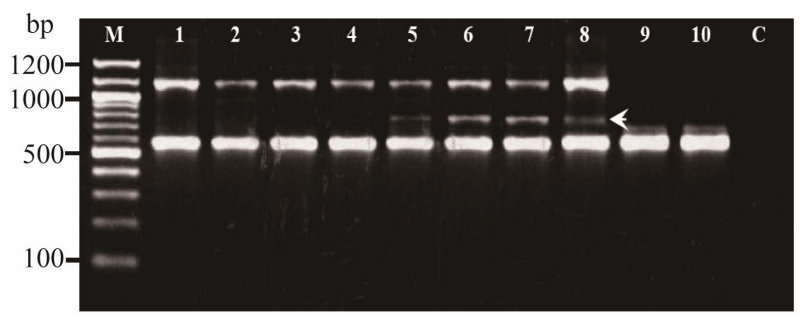

Figure 2. RAPD profiles of Cucumerinae species amplified with OPJ-11 on 1.5\% agarose gel. M: mole wt marker (100 bp), lane 1 - 4: C. sativus (samples collected from Khon Kaen, Udonthani, Loei and Nongbualamphu, respectively), lane 5 - 8: C. melo (samples collected from Khon Kaen, Udonthani, Loei and Nongbualamphu, respectively), lane 9 - 10: B. hispida (samples collected from Khon Kaen and Loei, respectively), and C: negative control. Arrow indicated the specific band.

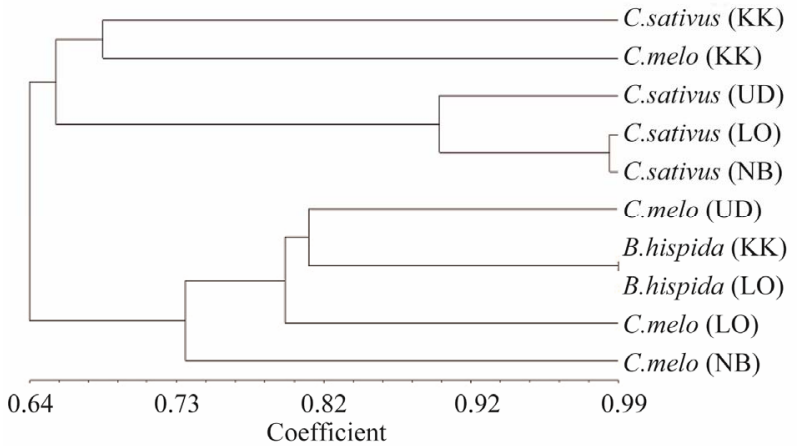

Figure 3. Dendrogram showing the relationship among the taxa of Cucumerinae (Cucurbitaceae), constructed by using UPGMA based on RAPD banding profiles. $C$. sativus, $C$. melo and $B$. hispida (samples collected from Khon Kaen (KK), Udonthani (UD), Loei (LO) and Nongbualamphu (NB), respectively.

Provinces) and C. melo collected from Khon Kaen Province belonged to the first clade, and the second clade consisted of two species of $C$. melo and B. hispida, the 
samples collected from the same 4 provinces as previous described (Figure 3).

\subsection{Cloning and Sequencing RAPD Markers}

The amplification product of 4 recombinant colonies of $\mathrm{Cm}\left(\mathrm{OPJ} 11_{700}\right)$ which putative positive transformant were identified based on the size of the amplification product (data not shown). The positive clones were used for DNA sequencing. The entire RAPD fragment of $\mathrm{Cm}$ (OPJ11 $1_{700}$ ) was sequenced using T7 and SP6 forward and reverse sequencing primers. The sequencing results showed that the cloned RAPD fragment $\mathrm{Cm}\left(\mathrm{OPJ} 11_{700}\right)$ had the correct size of $544 \mathrm{bp}$. Based on sequence information derived from cloned RAPD band, 17-mer oligonucleotide primer pair was synthesized for further use in PCR reactions (Table 1).

\subsection{Synthesis of SCAR Primers and PCR Analysis}

The designed SCAR primer pair name as Cm (SCJ11)17F (5'-GAGGCCGGTCATATCGA-3') and Cm (SCJ11)-17R (5'-ACCACGAATGTGTAGGA-3') was used to amplify genomic DNA from the four species (including: C. sativus, B. hispida, L. cylindrical and C. melo (collected from four different provinces of Thailand) (Table 1). Thermal cycling conditions for amplification using SCAR primers were optimized as described previously. A single, distinct and brightly resolved band of 516 bp was obtained in DNA isolated from all the $C$. melo specimens, and no non-specific amplification was observed in the other three Cucurbitaceae species (Figure 4). The faint bands on Figure 4, the DNA bands amplified genomic DNA from C. melo samples collected from Khon Kaen, Udonthani and Loei respectively, means there caused possible insufficient quantity or concentration of PCR product loaded on the gel.

\section{Discussion}

In this study, we have developed species-specific RAPD derived SCAR marker for identification of C. melo specimens. RAPD analysis can reveal high degree of polymorphism; does not require prior DNA sequence information of the species and is easy to perform. Therefore, various researchers have explored its application for authentication of traditional Chinese medicines like Panax ginseng [26], Echinacea [27] and Atractylodes [28]. In our RAPD analysis, significant genetic polymorphism was observed among the Cucumerinae species. We selected the common band approximately 700 bp; $\mathrm{Cm}\left(\mathrm{OPJ} 11_{700}\right)$ for all the C. melo specimens, which was absent in rest of the other Cucumerinae species for SCAR marker development. Several SCAR markers
Table 1. Sequences of RAPD fragment, Cm (OPJ11700) used in the development of SCAR markers, Cm (SCJ11516) specific to $C$. melo specimens.

\begin{tabular}{lc}
\hline bp & bequences of RAPD fragment \\
\hline 1 GCCAGATCAGACGCTCGAGGCCGGTCATATCGATTTGCTC & 40 \\
41 CGCCATCGATCTCCTCCGTCTTCATGCACCCTTCATTCTC & $8 \odot$ \\
81 GACGACCATAGGCTTCTTTTTCGGTTGCAGAAGCAGGTTA & 120 \\
121CTCCTAATTCTCCTCTCTCTCTCTCTCTCTCTCTCTCTCG & $16 \odot$ \\
161CTGATGCTGCCTGCCTACCTAATGCTGAATGTGCTACTTC & 200 \\
201CTTTTGTTTTCGCTAATTTGAGGGGGATATTTCCATTTTT & 240 \\
241TATCATTTGGCACTATGCAATTGGAAATCAAGAAAAATAG & 280 \\
281AATCCCTTTGTTTTGTAGCTAAACATCCTAGTCAGCGCAA & 320 \\
321CATCCTTTCTTCTATTCTTTTTTCCAATTACTTGTGTTGT & 360 \\
361TGGGGCTTTTGAGTTGATTCATTTCCTTTTTGGTGTTTAA & $40 \odot$ \\
401TCCTGTTTAGAAATTTATTGAGCTTTTGAGGAAAGGGACT & 440 \\
441CCAGAGGATCGAGATTTGGCCATTCAATGCCTTCGGACTG & 480 \\
481CACTCGCTCCTTGTGCTCTTGATGCATACCCGGTAACCAC & 520 \\
521GAATGTGTAGGAACGTTTGTTTTC & 544 \\
\hline
\end{tabular}

RAPD primer sequences are indicated in bold and the positions of SCAR primers are underlined.

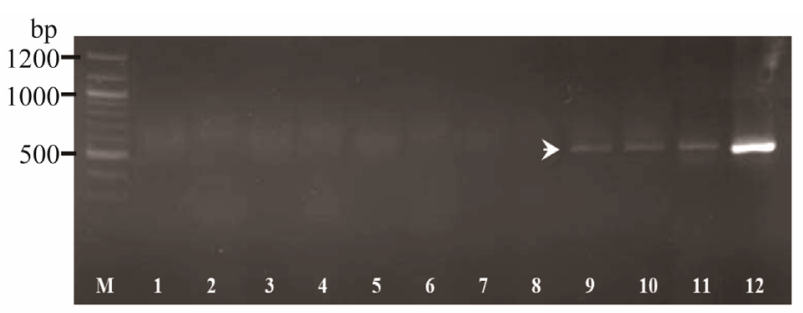

Figure 4. PCR amplification of Cucumerinae species using SCAR primers Cm (SCJ11)-17F and Cm (SCJ11)-17R on 1.5\% agarose gel. $M$ : mole wt marker (100 bp), lane 1 - 4: C. sativus (samples collected from Khon Kaen, Udonthani, Loei and Nongbualamphu, respectively), lane 5 - 6: B. hispida (samples collected from Khon Kaen and Loei), lane 7 8: Luffa cylindrical L. (collected from Khon Kaen and Udonthani), and lane 9 - 12: C. melo (samples collected from Khon Kaen, Udonthani, Loei and Nongbualamphu, respectively). Arrow indicated the specific band.

were developed for identifying to species and the resistance genes such as; SCAR markers developed from SSR marker to select the brown planthopper resistance gene in rice (Oryza sativa L.) [29], Paul et al. [17] converted RAPD markers to the SCAR markers used enables efficient sequence-specific marker for identifying different accessions of Momordica charantia L., and species specific SCAR markers designed from Internal Transcribed Spacer (ITS) 1 and 2 of the genus Phyllanthus [30]. Moreover, the RAPD markers were used to selection for drought tolerance in bread wheat genotypes [31], and Amir et al. [32] applied these markers for identifying nectariless trait in upland cotton. 
In SCAR, pairs of 17 bp oligonucleotide primers specific to the sequence of polymorphic bands can be used to amplify the characterized regions from genomic DNA under stringent conditions, which makes this marker more specific and dependable as compared to RAPD marker (Paran and Michelmore 1993). Based on the sequence of $\mathrm{Cm}\left(\mathrm{OPJ} 11_{700}\right)$, SCAR primer pair; $\mathrm{Cm}$ (SCJ11 $\left.1_{516}\right)-17 \mathrm{~F}$ and $\mathrm{Cm}\left(\mathrm{SCJ} 11_{516}\right)-17 \mathrm{R}$ was designed. Genomic DNA from all the $C$. melo specimens was found to be fragmented. Therefore, $\mathrm{Cm}$ (SCJ11 $\left.1_{516}\right)-17 \mathrm{~F}$ and $\mathrm{Cm}\left(\mathrm{SCJ} 11_{516}\right)-17 \mathrm{R}$ were designed to amplify a small region (516 bp) of $\mathrm{Cm}$ (OPJ11 $1_{700}$ ) to widen their application. Cm (SCJ11 ${ }_{516}$ )-17F and Cm (SCJ11 $\left.{ }_{516}\right)-17 \mathrm{R}$ generated 516 bp bands in all C. melo specimens, while no amplification was observed in other Cucumerinae species. These results substantiate the applicability of the designed primers as a tool for identification of C. melo specimens. However, the development of species-specific markers has become an objective of high priority in the breeding program.

\section{Acknowledgements}

This work was supported by the research funds from the National Research Council of Thailand, and the Division of Support and Development Research, Mahasarakham University, Thailand.

\section{REFERENCES}

[1] B. Sikdar, M. Bhattacharya, A. Mukherjee, A. Banerjee, E. Ghosh, B. Ghosh and S. C. Roy, "Genetic Diversity in Important Members of Cucurbitaceae Using Isozyme, RAPD and ISSR Markers,” Biologia Plantarum, Vol. 54, No. 1, 2010, pp. 135-140. doi:10.1007/s10535-010-0021-3

[2] M. A. Helm and V. Hemleben, "Characterization of a New Prominent Satellite DNA of Cucumis metuliferus and Differential Distribution of Satellite DNA in Cultivated and Wild Species of Cucumis and in Related Genera of Cucurbitaceae,” Euphytica, Vol. 94, No. 2, 1997, pp. 219-226. doi:10.1023/A:1002976408213

[3] A. Levi, C. E. Thomas, A. M. Simmons and J. A. Thies, "Analysis Based on RAPD and ISSR Markers Reveals Closer Similarities among Citrullus and Cucumis Species than with Praecitrullus fistulosus (Stocks) Pangalo," Genetic Resources and Crop Evolution, Vol. 52, No. 4, 2005, pp. 465-472. doi:10.1007/s10722-005-2260-2

[4] A. H. Paterson, S. D. Tanksley and M. E. Sorrells, "DNA Markers in Plant Improvement," Advances in Agronomy, Vol. 46, 1991, pp. 39-90. doi:10.1016/S0065-2113(08)60578-7

[5] M. Soller and J. S. Beckmann, "Genetic Polymorphism in Varietal Identification and Genetic Improvement," Tag Theoretical Applied Genetics, Vol. 67, No. 1, 1983, pp. 25-33. doi:10.1007/BF00303917
[6] K. Joshi, P. Chavan, D. Warude and B. Patwardhan, "Molecular Markers in Herbal Drug Technology," Current Science, Vol. 87, No. 2, 2004, pp. 159-165.

[7] J. K. W. Williams, A. R. Kubelik, K. J. Livak, J. A. Rafalski and S. V. Tingey, "DNA Polymorphisms Amplified by Arbitrary Primers Are Useful as Genetic Markers,” Nucleic Acids Research, Vol. 18, No. 22, 1990, pp. 6531-6535. doi:10.1093/nar/18.22.6531

[8] M. A. Afzal, M. M. Haque and S. Shanmugasundaram, "Random Amplified Polymorphic DNA (RAPD) Analysis of Selected Mungbean (Vigna radiata L. Wilczek) Cultivars,” Asian Journal of Plant Sciences, Vol. 3, No. 1, 2004, pp. 20-24. doi:10.3923/ajps.2004.20.24

[9] M. A. Karam, H. H. Elfayoumi and S. M. Mohamed, "Genetic Diversity and Taxonomic Status of Lotus glaber Mill Populations in Fayoum Depression,” Asian Journal of Plant Sciences, Vol. 5, No. 6, 2006, pp. 996-1001. doi:10.3923/ajps.2006.996.1001

[10] A. Naz, Z. A. Swati and I. A. Khan, "Studies on Genetic Diversity in Pakistani Wheat Varieties Using Randomly Amplified Polymorphic DNA,” Pakistan Journal of Biological Sciences, Vol. 9, No. 15, 2006, pp. 2858-2861. doi:10.3923/pjbs.2006.2858.2861

[11] P. W. Skroch, J. B. Dos Santos and J. Nienhuis, “Genetic Relationships among Phaseolus vulgaris Genotypes Based on RAPD Marker Data," Annual Report of Bean Improvement Cooperation, Vol. 35, 1992, pp. 23-24.

[12] B. K. Hoey, K. R. Crowe, V. M. Jones and N. O. Polans, "A Phylogenetic Analysis of Pisum Based on Morphological Characters, and Allozyme and RAPD Markers," Theoretical Applied Genetics, Vol. 92, No. 1, 1996, pp. 92-100. doi:10.1007/BF00222957

[13] G. L. Brown-Guedira, J. A. Thompson, R. L. Nelson and M. L. Warburton, "Evaluation of Genetic Diversity of Soybean Introductions and North American Ancestors Using RAPD and SSR Markers,” Crop Science, Vol. 40, No. 3, 2000, pp. 815-823. doi:10.2135/cropsci2000.403815x

[14] A. N. Kaga, N. Tomooka, Y. Egawa, K. Hosaka and O. Kamijima, "Species Relationships in the Subgenus Ceratotropis (Genus Vigna) as Revealed by RAPD Analysis," Euphytica, Vol. 88, No. 1, 1996, pp. 17-24. doi:10.1007/BF00029261

[15] I. Paran and R. W. Michelmore, "Development of Reliable PCR-Based Markers Linked to Downy Mildew Resistance Genes in Lettuce,” Tag Theoretical and Applied Genetics, Vol. 85, No. 8, 1993, pp. 985-993. doi:10.1007/BF00215038

[16] S. L. Lee, J. Weber and R. Mohamed, “Genetic Variation and Molecular Authentication of Selected Aquilaria Species from Natural Populations in Malaysia Using RAPD and SCAR Markers,” Asian Journal of Plant Sciences, Vol. 10, No. 3, 2011, pp. 202-211. doi:10.3923/ajps.2011.202.211

[17] A. Paul, S. Bandyopadhyay, P. Acharyya and S. S. Raychaudhuri, "Studies on Genetic Diversity of Twelve Accessions of Momordica charantia L. Using Morphological, RAPD and SCAR Markers," Asian Journal of 
Plant Sciences, Vol. 9, No. 8, 2010, pp. 471-478. doi:10.3923/ajps.2010.471.478

[18] J. Wang, Y.-H. Wai, F.-N. Ngan, P. P.-H. But and P.-C. Shaw, "Application of Sequence Characterized Amplified Region (SCAR) Analysis to Authenticate Panax Species and Their Adulterants,” Planta Medica, Vol. 67, No. 8, 2001, pp. 781-783. doi:10.1055/s-2001-18340

[19] M. Y. Lee, E. J. Doh, H. P. Chae, H. K. Young, S. K. Eung, B. S. Ko and S.-E. Oh, "Development of SCAR Marker for Discrimination of Artemisia princeps and A. argyi from Other Artemisia Herbs," Biological and Pharmaceutical Bulletin, Vol. 29, No. 4, 2006, pp. 629-663. doi:10.1248/bpb.29.629

[20] A. Anuniwat, A. Chaveerach, T. Tanee and R. Sudmoon, "Development of SCAR Markers for Species Identification of the Genus Nepenthes (Nepenthaceae)," Pakistan Journal of Biological Sciences, Vol. 12, No. 22, 2004, pp. 1455-1461. doi:10.3923/pjbs.2009.1455.1461

[21] M. Das, S. Bhattacharya and A. Pal, "Generation and Characterization of SCARs by Cloning and Sequencing of RAPD Products: A Strategy for Species-Specific Marker Development in Bamboo,” Annals of Botany, Vol. 95, No. 5, 2005, pp. 835-841. doi:10.1093/aob/mci088

[22] J. J. Doyle and J. L. Doyle, "A Rapid DNA Isolation Procedure for Small Quantities of Fresh Leaf Tissue," Phytochemical Bulletin, Vol. 19, 1987, pp. 11-15.

[23] J. I. Hormaza, "Early Selection in Cherry Combining RAPDs with Embryo Culture,” Scientia Horticulturae, Vol. 79, No. 1-2, 1999, pp. 121-126. doi:10.1016/S0304-4238(98)00204-0

[24] T. Mamiatis, E. F. Fritsch, J. Sambrook and J. Engel, "Molecular Cloning: A Laboratory Manual," Cold Spring Harbor Laboratory Press, New York, 1982. doi:10.1002/abio.370050118

[25] M. A. Serghini, C. Ritzenthaler and L. Pinck, "A Rapid and Efficient 'Miniprep' for Isolation of Plasmid DNA," Nucleic Acids Research, Vol. 17, No. 9, 1989, p. 3604. doi:10.1093/nar/17.9.3604
[26] J. Y. Um, H.-S. Chung, M.-S. Kim, H.-J. Na, H.-J. Kwon, J.-J. Kim, K.-M. Lee, S. J. Lee, J. P. Lim, K.-R. Do, W.-J. Hwang, Y.-S. Lyu, N.-H. An and H.-M. Kim, "Molecular Authentication of Panax ginseng Species by RAPD Analysis and PCR-RFLP,” Biological Pharmaceutical Bulletin, Vol. 24, No. 8, 2001, pp. 872-875. doi:10.1248/bpb.24.872

[27] H.-T. Wolf, I. Zündorf, T. Winckler, R. Bauer and T. Dingermann, "Characterization of Echinacea Species and Detection of Possible Adulterations by RAPD Analysis," Planta Medica, Vol. 65, No. 8, 1999, pp. 773-774. doi:10.1055/s-2006-960866

[28] K. T. Chen, Y. C. Su, J. G. Lin, L. H. Hsin, Y. P. Su, C. H. Su, S. Y. Li, L. H. Cheng and S. J. Mao, "Identification of Atractylodes Plants in Chinese Herbs and Formulations by Random Amplified Polymorphic DNA,” Acta Pharmacologica Sinica, Vol. 22, No. 6, 2001, pp. 493 497.

[29] S. Santhanalakshmi, S. Saikumar, S. Rao, A. SaiHarini, P. Khera, H. E. Shashidhar and P. Kadirvel, "Mapping Genetic Locus Linked to Brown Planthopper Resistance in Rice Oryza sativa L.," International Journal of Plant Breeding and Genetics, Vol. 4, No. 1, 2010, pp. 13-22. doi:10.3923/ijpbg.2010.13.22

[30] S. Bandyopadhyay and S. S. Raychaudhuri, "Development of ITS Based SCAR Markers for Some Medicinally Important Species of Phyllanthus," Asian Journal of Plant Sciences, Vol. 9, No. 5, 2010, pp. 264-270. doi:10.3923/ajps.2010.264.270

[31] A. H. Gorji, F. Darvish, M. Esmaeilzadehmoghadam and F. Azizi, "Application RAPD Technique for Recognition Genotypes Tolerant to Drought in Some of Bread Wheat," Asian Journal of Biotechnology, Vol. 2, No. 3, 2010, pp. 159-168. doi:10.3923/ajbkr.2010.159.168

[32] A. H. Amir, T. A. Malik , H. Raza and M. U. Rahman, "DNA Marker Studies for Leaf Nectaries in Upland Cotton,” Asian Journal of Plant Sciences, Vol. 1, No. 4, 2002, pp. 395-396. doi:10.3923/ajps.2002.395.396 